\title{
56
}

\section{Teaching and learning with telecommunications: issues for schools and professional development}

\author{
Niki Davis \\ University of Exeter \\ United Kingdom
}

\begin{abstract}
There is a wide range of applications for telecommunications in teaching and learning, but unlike in commerce and in leisure these are peripheral rather than part of the infrastructure. Applications range from information retrieval to information provision: using computerized banks of information to electronic mail to multimedia communication incorporating video conferencing on the desktop. This paper reviews the issues which prevent video and telecomputing from becoming a main stream activity in teaching, learning and professional development. It suggests that the extreme changes in practice required by telecommunications imply a move towards applications which directly address the needs of the institution and community including the business community. Telecommunications are too costly and hopefully too valuable to be repressed in education.
\end{abstract}

Main conference themes: infrastructure, resources

Educational areas: primary education, secondary education, professional development

Study topics:

Secondary keywords: telecommunications, electronic mail, networks, teleteaching 


\section{INTRODUCTION}

Telecommunications, particularly Information Technology (IT) with communications or telematics telecomputing, are becoming widely used in education. This is particularly evident in the USA where the government is promoting an 'Information Superhighway'. The European Union is also considering a Trans European Network. However most of the applications being generated will not become fundamental to education. These are most frequently perceived as add-on activities which are valuable for basic skills and cross curricular purposes. Such justification is valuable for new projects and enthusiasts, but is unlikely to result in sustained and widespread application. The reverse situation occurs in commerce and leisure where telecommunications with IT has revolutionized practice. This paper reviews the use and discusses the issues which appear to impede telecommunications from becoming as important an infrastructure to education as it is within commerce and leisure.

\section{The range of telecommunications}

The classification of IT telecommunications according to technology or media used is now breaking down as the tools merge into one another: a video picture is now possible on the personal computer screen (for example British Telecom's VC 8000) and software running such a window probably gives all the facilities for audio-graphics. Other windows into the Internet collections of information and into discussions in computer conferences can be added too. Similarly video projection systems permit these applications to be used with small or large groups. Satellite transmission of one way video is now being supplemented with limited two way communication. It therefore appears that the technologies themselves do not offer a good structure for a classification.

The change from a technical approach is reinforced in the following quote from Laurillard which emphasizes the social dimension so important to communication:

"New teaching methods, such as educational media, depend for their success upon being properly embedded into the existing learning context. Innovation will necessarily require changes in what exists already, and if this is not acknowledged and accommodated, then the innovation will not succeed." ([1], p. 221)

\section{Practice with telecommunications in education}

Telecommunications can support a number of teaching and learning activities in education. These can be roughly placed on a continuum from information 
retrieval to information provision as shown in Table 1. Telecommunications can also change the role of the student so that they become apprentices in a number of fields: collecting data and interpreting it with other pupils and scientists, working with an author to write novels, collecting articles and producing a newspaper, and using real information sources provided by pupils in another location and returning the favour for those pupils. The connection of learners provides them with an audience for whom they will write possibly in a target language which is that of their audience, but not their own. While these activities are possible using traditional post or visits, the timeliness of the communication permits learning to take place within the attention span of the pupils and the school timetable. Information provided by pupils in another location is not mediated by the publishing process and such 'raw' data is frequently more relevant to the pupils than that in a text book. Where time permits additional questions can be posed to explore the data and correct misunderstandings.

\section{Telecommunications in schools}

Telecommunications are used in education all around the world. The highest current use is probably in the USA with Australia making particularly high usage for remote teaching. There is some indication that where there is no charge for local calls telecommunications are more common. Honey and Henriquez [2] report a national survey of 500 experienced school teachers who were active users of telecommunications technology for professional development and student learning. The main findings were that the teachers valued telecommunications both for student learning and their own professional development. These teachers act as facilitators and as a resource for their colleagues. They are well endowed with technology and have used computers for instructional purposes for more than eight years on average. There was general agreement that the use of telecommunications had changed teaching practices, increasing student autonomy and encouraging students' higher level thinking processes. This echoes findings with computer use of teachers generally.

Telecommunications were perceived to be most effective for student projects in science and social or cultural exchanges. News services and scientific databases were rated the most useful information retrieval activities. The incentives perceived by teachers included the expansion of students' awareness about the world, access to information otherwise difficult to obtain and increasing students' inquiry based and analytical skills. Key factors which are by the way influencing the success of any shared learning activity, were planning, cooperation, and also well-defined and relevant project goals. 
Table 1 Telecommunication activities in education: ordered from information retrieval to information provision

Banks of Information

- many of the world's library catalogues are available to search on the Internet

- NASA provides data from its space missions

- files on current issues produced for research or 'political' purposes

- government or regional information

Real artefacts to use

- full texts of newspapers or Reuters' pre-published material

- full texts of classical books

- weather and acid rain data in the form of Quicktime movies, e.g. Blue Skies

- slow scan video of another spot on earth

Resources to use from a distance

- supercomputing

- simulations

- scientific, geographic and mathematical data

- teleportation by touch and sight are all becoming possible

\section{Project work}

- learning circles (overlapping sets of six on a common theme)

- Newspaper Days with news collection and publication

- projects on current or historical issues

- science or mathematics projects promoting learner participation

Discussions to monitor and/or join (or advise, manage etc.)

- computer education issues

- teacher education, e.g. science

- getting to know learners in different places, e.g. Kidsnet

- case conference discussing a shared issue or context

\section{Teaching of a topic}

- presentation of a lecture or an argument possibly video conference

- presentation and organization of a topic, possibly including assessment

- collaborative teaching/learning of a set of related topics

- demonstration and/or workshop using IT tools at a distance

\section{Individual communication}

- making and planning appointments, teaching etc.

- feedback on assessment, performance etc.

- collaborative writing of papers, grants etc.

- asking for a specific piece of information or help 
Communicating with other educators, accessing information and combating professional isolation were the most highly rated incentives for professional activities with about one quarter of the teachers using telecommunications daily for collegial exchanges and information retrieval.

A particularly supportive approach to teachers who wish to use telecommunications in education, is the AT\&T 'learning circle'. This telecommunications service provides and coordinates not only the telecommunications, but also the clear routine for their use which ends with a product all participants can be proud of. There is also technical support and 'match-making' promotes good collaboration and ownership of the process by all of those involved. A recent evaluation of this teaching strategy used the novel approach of testing students for the sort of skills requested by employers [3]. The 110 teachers surveyed reported gains in all skills requested by employers plus in areas such as creativity, communication and motivation. The teachers, perhaps surprisingly, rated the effects on their own professional development higher than the student outcomes.

Early research into telecommunications in the UK was reported in Smith [4]. Most of the issues continue to be relevant: the need for close collaboration, the important role of a facilitator, issues of access and ease of use, the value of an international community, professional support for teachers and the role of a range of telecommunications including satellite television in open and distance learning. The case study reported by Somekh and Groundwater Smith provides a clear description of the way in which young learners can engage with a profound philosophical question, while developing language skills and making judgements for the benefit of their audience on the other side of the Atlantic. A later overview is provided by Keep [5] and the educational potential of three more recent cases are described and discussed in Davis [6].

The description of telematics (telecommunications with IT) in Europe by Veen et. al. [7] includes the UK among the national descriptions and case studies of projects. The introduction to the book identifies common issues which emerge:

- policies vary across the countries from laissez faire to central government funding;

- many activities focus on student use of e-mail and on-line databases with the conclusion that the activities are highly motivating for the students. but require very strict planning;

- other activities focus on the professionalization of teachers (this is of increasing importance to the aims of the European Union); 
- telecommunications with IT demand new forms of teaching and learning which imply changes in teaching behaviour, and this requires both facilitation and support. The cost of telecommunications appears to be a real drawback with a consequent demand for new charging structures from telecom companies;

- important technical aspects include ease of use and easy ways for navigating through databanks;

- there is, as yet, little European cohesion and exchange between the projects.

It is possible that the European Union will create its own Trans European Network to stimulate cooperation between the member countries, as has been created between the Nordic countries in 1994.

\section{Teacher education with telecommunications}

Applications in teacher education have stretched from information banks to projects and consultancy. Early information banks provided catalogues, materials and notice boards to support changes in the curriculum (for example ResCue on Campus 2000 in the UK). Today less formal banks of information are accessible through the Internet, frequently as a byproduct of educational and research activities. A Teacher Education Internet Server (TEIS) is part of this. It is a collaborative venture of teacher educators in the USA and UK which aims to address the needs of staff in faculties, research students and student teachers.

ResCue's success was limited by issues of access. Teachers lack of computer awareness and the unreliable nature of e-mail a few years ago accentuated the difficulty of sharing resources within one institution [8]. Such barriers have been reduced especially where individual teachers have their own mail box and modem. However the need for sophisticated equipment and payment for access still limits use.

Project work has also proved valuable. Meadows [9] describes some general factors which affect successful international projects: their time consuming nature, the need for careful preplanning between teachers on the different sites, the cost of telecommunications especially when exploring databases, the access to computers, software and telephones both in college and in schools, the training and support required by new users and the timing of messages. There is a wide range of suitable topics: social, cultural and environmental topics are obvious and alternative conceptions of science have also been used successfully. Harris [10] provides more models for integration of telecomputing into precollege curricula split into interpersonal exchanges, information collections and problem solving projects. These are also relevant 
for preservice courses especially when student teachers assist in projects for children.

Projects are becoming increasingly difficult to organize in the UK due to increased school based training. The need is therefore to provide student teachers in schools with effective on-line access to library catalogues and tutor and peer group discussions. In the USA the use of telecomputing has been shown to increase the reflection of student teachers who share their 'teaching journals' with their supervisors and fellow students by electronic mail.

Point to point telecomputing can provide an intensive session of teacher education especially when two phone lines are available to provide a multimedia link [7]. Once connected the tutor and the school staff look at the same screen and both have access to the same keyboard with the software running on one of the PCs. In addition the voice line provides immediate and friendly contact, which minimizes the mystery of the IT and gives the school staff control over their own progress.

Newman and Hunter describe an exciting set of projects in the USA which aim to develop communities of learning. Copernicus servers offer an advanced range of telecommunications tools which are easier to use in the curriculum than earlier systems. Newman and Hunter's starting point recognized that equality of access will require contributions from many sectors, so they posed the following question:

"Can the technology bring educational benefits sufficient to attract large scale investment by local, state and federal agencies, as well as industry?" ([11], p. 1)

One of the guiding principles in the projects is that a selfsustaining community of practice can be formed. The contrasting set of projects are for example addressing the following issues:

- A community of explorers in a high school science project has exchanged experimental data including scenarios and other files. The teachers found that time either had to be spent building a local community or the teacher participated alone in the larger community and gradually changed local conditions. They also found access to the university library catalogue, ERIC databases and various Gopher searches valuable. Professional development opportunities were a necessary and valuable part of the process.

- InternNet was for teacher preparation concerning curriculum development and teaching especially Internet resources (20 interns and their university tutors). For most interns who had not used the medium before, it was too novel and impersonal to trust in a high stress programme. It is now being 
re-evaluated to include use before placement in school and for use between interns themselves for peer support.

- Regional and state department information and communication have caused district and state authorities to recognize that participation will be of greater value if linked to their broader purposes and to locations beyond schools, such as libraries and museums.

A major finding in the projects is the need for significant training and/or staff selection. The required skills are largely nontechnical. The community requires a facilitator to form and that person, or those people, need to understand the values and ethos of their colleagues. Telecommunications need to be linked to larger or more immediate goals. Newman and Hunter also recognized their error in assuming 'that networking (telecommunications) projects are add-on activities that carry with them their own value.' ([11], p. 25)

\section{RESUME OF ISSUES}

The first most important factor is the need to communicate and to make telecommunications with IT become an on-going activity rather than an occasional 'binge'. New practices in relation to teaching and learning also need to be established, so purposes must be clear and must relate to all participants' agendas.

Access is a second major issue. Access must be easy, preferably in 'home' area with proper training and support. The software interface should be a common one. Telephone lines need to be accessible. Many projects note the depth of knowledge, selfesteem and autonomy developed by students who control the communication themselves, with teacher support and supervision.

Group work in the classroom and group work across remote sites causes difficulties of its own. A 'match maker' and consultant has proved powerful even where telecommunications with IT are part of a course. Also an organizer directing the communication may help interaction develop. Baker et. al. [12] provide a checklist for facilitators in on-line collaboration derived from analysis of computer conferencing. A help desk is useful initially, but less important when other participants can offer advice. For these reasons centralized systems have advantages, but access to facilitators is more important than centralization of the technology.

One successful strategy for those using foreign languages has been to use both languages such that participants write in their own language, but read in the other. The use of written communication does assist those who have difficulty communicating orally, for example in the Chatback project. In the 
UK Project GEMENI has stimulated the use of more than one telecommunications channel to good effect, for example both satellite and fax. One form of electronic communications can complement the other [7].

Point to point multimedia telecommunications highlight additional issues. There is some frustration with the delays because the immediate response of audio is unmatched by computer or video display. Delays over ten seconds disrupt real time communication completely. Sessions must be better planned than informal tutoring and take much longer than a face to face session. Lack of synchronization between media or applications is distracting. Timetabling of systems is complex. Other problems relate to navigation, control and resolution and bandwidth available for transmission.

\section{CONCLUSION}

The volume of activities in educational telecommunications has never been higher but there is some anxiety that it will fade away, leaving only the enthusiasts who are prepared to add it on to their workload because it gives them a buzz and they can see their students' gain from the activity. Most people have mistakenly assumed that telecommunications are 'good for education' without close examination of what they are 'good for' and the issues that this raises.

The most important issue must be that integrating new forms of communication into education will change the old routines. The addition of a telecommunications infrastructure to education will make a fundamental change in pedagogy. This paper tries to help in developing a pedagogy which incorporates telecommunications, rather than leaving telecommunications on the periphery of education as an add-on activity. Telecommunications are too costly and hopefully too valuable to repress in this way.

\section{ACKNOWLEDGEMENTS}

I would like to acknowledge the support of my colleagues around the world, my University and funding agencies such as The UK Department of Employment Learning Methods Branch, Higher Education Funding Council and British Telecom PLC.

This paper is based on research in telecommunications and in teacher education. Many references have had to be omitted through the need for brevity. 


\section{REFERENCES}

1. Laurillard, D. (1993) Rethinking university teaching: a framework for the effective use of educational technology. Routledge: London.

2. Honey, M. and Henriquez, A. (1993) Telecommunications and K-12 educators: findings from a national survey. Center for Technology and Education, Bank Street College of Education, New York. pp. 41- .

3. Riel, M. (1994) The SCANS report and the AT\&T Learning Network: preparing students for their future. Telecommunications in Education News, 5, 1, pp. 10-13.

4. Smith, D. (ed) (1988) New technologies and professional communications in education. Occasional paper 13, National Council of Educational Technology, Coventry.

5. Keep, R. (1991) On-line: electronic mail in the curriculum. National Council of Educational Technology, Coventry.

6. Davis, N. E. (1994b) Electronic communication. In Underwood, J. (ed) Computer Based Learning: potential into practice. David Fulton Publishers, London, pp. 41-60

7. Veen, W., Collis, B., de Vries, P. and Vogelgang, F. (eds) (1994) Telematics in education: the European case. Academic Book Centre: De Lier, The Netherlands.

8. Somekh, B. (1989) The human interface: hidden issues in CMC affecting use in schools, in Mason, R. and Kaye, A. R. (eds.) Mindweave. Oxford: Pergammon.

9. Meadows, J. (1992) International collaborations in teacher education: a constructivist approach to using electronic mail for communication in partnership with schools. Journal of IT in Teacher Education, 1 (1) pp. 113125.

10. Harris, J.(1994) A model for integration of telecomputing in pre-college curricula, in Willis, J, Robin, B and Willis, D. A. (eds.) Technology and Teacher Educational Annual 1994. AACE, Charlottesville, pp. 637-642. 
11. Newman, D. and Hunter, B. (eds.) (1994) Preliminary report on phase 1 of the national school network testbed. Bolt Beranek and Newman Inc., Cambridge, MA.

12. Baker, T. L., Obermeyer, G., Jervis, K. and Aldine, S. (1994) Saving faceto-face: Network moderators and the construction of collaborative space for school restructuring. AREA annual conference. 